\title{
A Zona Franca de Manaus e o capitalismo no Brasil
}

JOSÉ SERÁFICO e MARCELO SERÁFICO

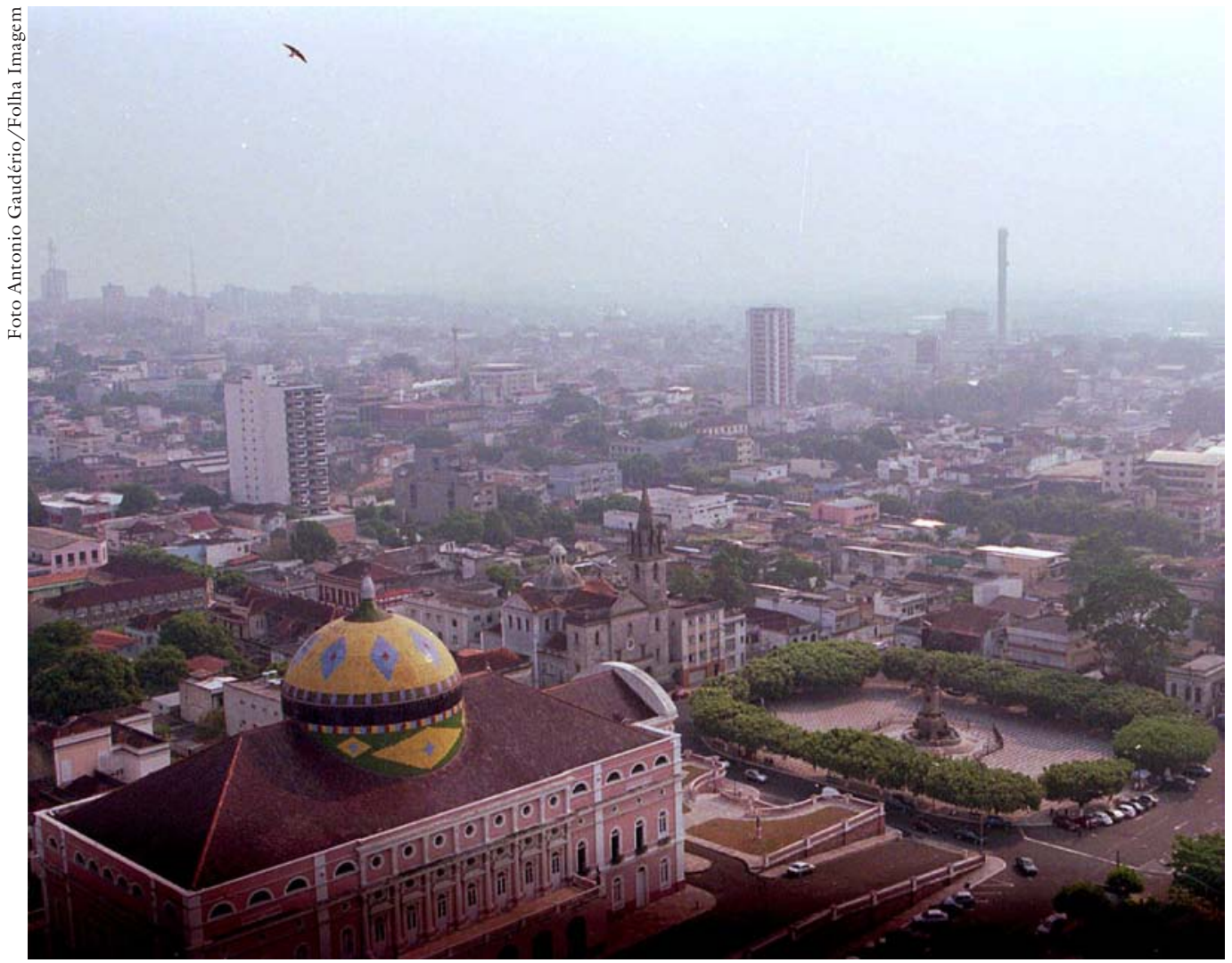

Vista da área central da capital do estado do Amazonas, Manaus

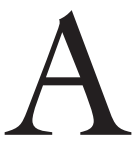

S EXPECTATIVAS de integração à nação e as ameaças, virtuais ou concretas, de internacionalização, são constantes na história da Amazônia. Pode-se mesmo dizer que a própria Zona Francal é um emblema dessas expectativas e ameaças. Considerando-se suas origens e história, porém, pode-se compreendê-la como um exercício de economia política dos governos brasileiros inserido no processo de transformação de um modelo de desenvolvimento de capitalismo nacional em outro de capitalismo associado.

A criação da Zona Franca de Manaus foi justificada pela ditadura militar com a necessidade de se ocupar uma região despovoada. Era necessário, portanto, dotar a região de “condições de meios de vida" e infra-estrutura que atraíssem para ela a força de trabalho e o capital, nacional e estrangeiro, vistos como 
imprescindíveis para a dinamização das forças produtivas locais, objetivando instaurar na região condições de "rentabilidade econômica global". De fato, sua criação e desenvolvimento sempre estiveram atrelados a circunstâncias políticoeconômicas locais, nacionais e mundiais.

Mundialmente, a Guerra Fria forçava a opção nacional entre conservar-se na área de influência norte-americana ou encaminhar-se para a soviética; além disso, avançava o processo de descentralização industrial ${ }^{2}$, impulsionado pelas inovações nas comunicações e transportes, pela indústria eletrônica e pela organização dos trabalhadores nos países industrializados. Nacionalmente, a resolução das tensões relativas ao aprofundamento da democracia burguesa e, no limite, ao socialismo, deu-se nos termos do Golpe de Estado de 1964 e da implantação da ditadura militar, que conduziu a política econômica nacional de modo a privilegiar o capital estrangeiro no processo de apropriação e uso das forças produtivas do país. Localmente, mantinha-se a estagnação econômica legada pelo fim do "ciclo da borracha" e apenas brevemente superada pelos Acordos de Washington, de 1942.

É nesse contexto que a Operação Amazônia, de que a Zona Franca de Manaus é um capítulo, adquire sentido. Talvez se possa vê-la como uma espécie de síntese desse quadro global, na medida em que é ela que resolve, no plano nacional, o modo por meio do qual ocorreria a regionalização do desenvolvimento capitalista. Isto é, a Operação Amazônia compatibiliza o discurso nacionalista do militarismo com as reivindicações acerca do desenvolvimento regional da Amazônia e com o processo de transnacionalização do capital.

Vale a pena retomar um pouco dessa história para compreender como, no jogo entre expectativas de integração à nação e impasses gerados pela internacionalização, a Zona Franca vem, progressivamente, se convertendo num espaço de relações globais.

Desde o fim dos Acordos de Washington, a economia da Amazônia, de um modo geral, e do Amazonas, em específico, via-se órfă de políticas do governo federal que permitissem a reprodução local do desenvolvimento experimentado pelo Centro-Sul do país.

De fato, no modelo de desenvolvimento econômico nacional fundado na industrialização por meio da substituição de importações parecia não haver espaço para a reprodução dos interesses das elites locais, dos proprietários de seringais, madeireiros etc. Daí o pronunciamento do Deputado Francisco Pereira da Silva (PSD/AM), em 6 de agosto de 1957:

Há quem afirme, Sr. Presidente, não merecer maiores preocupações essa nova etapa de nossa política econômica, em relação à goma elástica, pelo aparecimento de fábricas de borracha sintética no País. Argumenta-se, por exemplo, que as exigências de consumo, a marcha acelerada do nosso progresso, o programa da indústria automobilística vão exigir, a partir de 1960, um tão grande volume de borracha que, mesmo havendo todo o estímulo à produção, todo o auxílio financeiro ou de qualquer natureza às explorações silvestres e ao plantio da cultura das heveas, as safras não corresponderão às exigências fabris. 
O argumento, porém, excessivamente pessimista para a borracha nativa e na base de um aceleramento industrial que, sendo possível, todavia está subordinado a fatores negativos, de interferência inevitável, no campo da produção de artefatos, merece, portanto, apreciação mais adequada aos fatos. A verdade é que as necessidades da indústria, modificados para melhorar os processos de produção, facilitados os financiamentos e a entrada de pessoal para a faina extrativa, poderão ser supridas pela borracha natural.

De qualquer forma, Sr. Presidente, o quadro é impressionante. Daí por que solicitamos para ele a atenção do nosso ilustre e preclaro Ministro José Maria Alkmin, para que atenda, o mais rapidamente possível, às modestas e justas aspirações dos seringueiros e seringalistas, talvez os mais esquecidos e deserdados dos brasileiros, e, assim, não concorra, com a sua alta e sensível responsabilidade, para agravar uma crise que se arrasta por muitas décadas, sem solução corajosa e decidida ${ }^{3}$.

O deputado tem clareza quanto ao "perigo" representado pela substituição da "borracha natural" pela "borracha sintética", mas também tem convicção quanto às oportunidades que podem decorrer para os seringalistas da expansão da demanda por borracha. Seu argumento, porém, visa a requerer o aumento dos subsídios à extração da borracha num momento em que as atenções do governo federal estão tomadas pelas possibilidades de substituir importações, tendo em vista aprofundar a industrialização do país.

Do ponto de vista do líder político local, a manutenção dos subsídios à borracha significava a preservação da renda dos seringalistas e uma possibilidade de integração do setor gomífero à dinâmica desencadeada pela industrialização do Centro-Sul do país; do ponto de vista do governo federal, porém, significava desperdício de recursos que poderiam ser carreados para a "modernização" do parque industrial e para o atendimento dos objetivos do Plano de Metas, isto é, da realização em cinco anos daquilo que, em outras circunstâncias, levaria cinqüenta, e que teve como emblema a construção de Brasília.

O próprio deputado Francisco Pereira da Silva parecia dar-se conta da necessidade de se encontrar novas soluções para a economia local. Pois foi ele quem apresentou à Câmara do Deputados o Projeto de Lei no ${ }^{\circ}$ 1.310, de 23 de outubro de 1951, em que propõe a criação em Manaus de um porto franco. Este projeto é que, emendado pelo deputado Maurício Joppert, foi convertido na Lei $n^{\underline{o}}$ 3.173, de 6 de junho de 1957, transformando o porto em Zona Franca de Manaus. Não obstante sua regulamentação pelo Decreto nำ 47.754, de 2 de fevereiro de 1960, a Zona Franca só entra em vigor, efetivamente, a partir de 28 de fevereiro de 1967, quando é reestruturada pelo Decreto-Lei no 288.

Essa trajetória de quase dezesseis anos entre a apresentação do Projeto de Lei n ${ }^{\circ} 1.310$ e a assinatura do Decreto-Lei no 288 foi acompanhada pela sistemática frustração das expectativas de setores da sociedade local quanto a medidas federais que permitissem a redinamização econômica do estado. Isso se evidencia, por exemplo, nas palavras de Arthur Reis, ex-governador do Amazonas e exdiretor do Instituto Nacional de Pesquisas da Amazônia: 
Encerrado o conflito (a II Guerra Mundial], voltamos ao desinteresse mais intenso ou mais incisivo. As medidas descontinuadas que se decretaram não surtiram efeito de maior monta. Criou-se por determinação constitucional, uma Superintendência para o Plano Qüinqüenal que deveria executar-se para a valorização regional. Devo prestar um depoimento. Além de Getúlio Vargas, que presidia o Brasil, em nenhum homem público nacional com responsabilidade no governo, encontrei a menor ressonância. Se não havia má vontade, havia desinteresse, despreocupação, ignorância da matéria, falta de consciência de qualquer espécie. Toda sorte de obstáculos tive de enfrentar. Tudo se fez para que a Superintendência [do Plano de Valorização da Amazônia SPVEA] falhasse, desmoralizando-se a iniciativa. Aconteceu o mesmo com relação ao Instituto Nacional de Pesquisas da Amazônia, criado como resposta brasileira ao Instituto da Hilea, sugerido pelo Brasil, mas projetado para finalidades contrárias aos nossos mais legítimos interesses ${ }^{4}$.

Num certo sentido, a "descontinuidade das medidas", o "desinteresse", a “despreocupação", a "ignorância” e a "falta de consciência” a que alude Arthur Reis podem ser vistos como um modo específico de compreender o que eram, de fato, limites da dinâmica do projeto de capitalismo nacional no que concernia à integração da região à nação.

De fato, o modelo de desenvolvimento orientado pela industrialização via estratégia de substituição de importações e fundado na política de massas, no dirigismo estatal e na política externa independente ${ }^{5}$ reservou à Amazônia uma posição secundária no processo de dinamização econômica que instaurou e no projeto de formação social que engendrou.

Não é à toa, portanto, que, do ponto de vista de alguns segmentos da sociedade local, a sensação de abandono, esquecimento e incompreensão predominante cedeu, a partir da Operação Amazônia, à de esperança e alento. Em princípio, pode parecer um paradoxo a volta da Amazônia à “consciência nacional" no momento preciso em que as classes dominantes no país decidem engajarse em um projeto de capitalismo associado, no qual predominam os interesses e a dinâmica do capital transnacional, via "política de interdependência". Mas, como explica Silva, o problema mostra-se como uma oportunidade de equacionar, combinar elementos aparentemente incompatíveis:

O que aparentemente é um problema - a cooperação entre o militarismo, a economia mundial e o nacionalismo - faz parte de um momento definido da ordem internacional. Essa concatenação de interesses determina a escolha do lugar de experimentação de uma das primeiras zonas francas do mundo; determina também os modos de compatibilizar a "ordem nacional" com a "ordem mundial"; e, finalmente, determina a contrapartida que os países "periféricos", “dependentes", podem obter por constituírem-se em área de expansão da acumulação capitalista. O que importa é reforçar que a concepção e a decisão de implantação da Zona Franca de Manaus são oriundas de processos e relações mais amplas que efetivam um movimento de descentralização da produção capitalista fora das suas zonas originárias ${ }^{7}$. 
Isso permite observar a Zona Franca de Manaus como um duplo movimento do Estado militarista no sentido, de um lado, da implantação de uma área de "livre comércio, de importação e exportação e de incentivos fiscais especiais" a partir da qual ele reafirma o compromisso do Brasil com o "sistema de mercado", assegurando sua permanência como "área de influência" dos EUA no contexto da Guerra Fria; de outro lado, no sentido da criação das condições jurídico-políticas e de infra-estrutura local necessárias à atração de investimentos estrangeiros, num momento em que avança a descentralização industrial ${ }^{8}$.

Na verdade, a Zona Franca - como o próprio Golpe Militar de 1964 configura-se como uma das formas de superação das tensões que punham em jogo algumas das condições de manutenção e expansão da acumulação capitalista no Brasil ${ }^{9}$; sendo, porém, a combinação da estagnação econômica local, com o movimento no sentido da descentralização industrial e o surgimento de outras zonas francas na região ${ }^{10}$ fatores, dentre outros, decisivos para que a geopolítica do militarismo defina Manaus como o espaço para a criação de uma zona franca.

Cabe, quanto a isso, senão uma negação da tese que associa a implantação das zonas francas a governos autoritários, pelo menos uma relativização. Na verdade, o pressuposto histórico fundamental para a implantação de uma zona franca tem a ver com a convergência de dois fatores: de um lado, a possibilidade das empresas dos países industrializados de descentralizarem seus processos produtivos e, de outro, a existência em outros países de condições jurídico-políticas e econômicas que assegurem a redução dos custos de produção e a ampliação dos mercados consumidores de determinadas mercadorias - a serem consumidas improdutiva ou produtivamente ${ }^{11}$.

No caso específico de Manaus, a estagnação econômica tanto contribuía para rebaixar o valor da força de trabalho ${ }^{12}$ quanto para aumentar a concorrência entre os trabalhadores por emprego, o que implicava dificuldades para sua organização política ${ }^{13}$. Num tal contexto, o papel da ditadura parece ter sido, principalmente, o de criar algumas das condições que permitissem ampliar as oportunidades de investimento capitalista e controlar a força de trabalho num processo em que esta se integrava em situação bastante frágil ${ }^{14}$.

Esse era o espírito da Exposição de Motivos no $21^{15}$, de 27 de fevereiro de 1967, que serviu de base para o Decreto-Lei no 288, quando se refere à "falta de rentabilidade econômica global" decorrente da orientação básica da Lei no 3.173 e do Decreto no 47.757 que a regulamentava:

2. Conforme concebido originalmente, na Zona Franca de Manaus:

a) haveria uma área não inferior a 200 hectares, onde ficaria localizada a Zona Franca, completamente isolada da cidade de Manaus;

b) o governo federal teria jurisdição sobre a área da Zona Franca;

c) seriam construídas pelo governo federal, as instalações de armazenagem, portuárias e industriais necessárias ao funcionamento da Zona.

3. As inversões federais necessárias para a criação da infra-estrutura básica da Zona 
Franca de Manaus são de tal maneira vultosas em face do produto obtido da criação de novas indústrias numa área limitada, que todos os projetos de desenvolver a Zona Franca estão destinados ao fracasso por falta de rentabilidade econômica global. Além disso, não foram criadas condições de meio de vida local, capazes de atrair para essa região a mão-de-obra técnica.

A superação desses limites implicaria considerar-se a adoção de medidas no sentido de:

- estabelecer uma área mínima de $10 \mathrm{mil} \mathrm{Km}^{2}$, incluindo a cidade de Manaus e seus arredores;

- isenção fiscal de importação para as matérias-primas e produtos destinados à Zona Franca de Manaus;

- isenção de impostos de exportação para o estrangeiro;

- equivalência de exportação brasileira para o estrangeiro àqueles produtos destinados à Zona Franca, a fim de permitir condições de concorrência da produção nacional com a importação estrangeira.

Essas críticas e recomendações foram incorporadas ao Decreto-Lei n $\underline{0} 288$, que ampliou os incentivos fiscais para as empresas que se estabelecessem na zona franca; ao Decreto nํ 291, de 28 de fevereiro de 1967, que estendeu a área dos incentivos fiscais para toda a Amazônia Ocidental (Amazonas, Acre, Rondônia e Roraima); e ao Decreto no 61.244, de 28 de agosto do mesmo ano, que criou a Superintendência da Zona Franca de Manaus, órgão do governo federal encarregado da administração dos incentivos fiscais da zona franca.

Essa reestruturação inseria-se no processo mais amplo de implantação de zonas francas no mundo ${ }^{16}$, acompanhado, sistematizado e difundido pela Organização das Nações Unidas para o Desenvolvimento Industrial (Onudi).

De acordo com o documento Industrial Free Zones as Incentives to Promote Export-Oriented Industries, apresentado pela secretaria da Onudi no Seminário de Treinamento sobre Zonas Francas Industriais, em 1971, havia no mundo, até então, apenas três exemplos de "zonas de processamento de exportação": Kaoshiung (República da China), Shannon (Irlanda) e Kandla (Índia). Não obstante, outros trinta países em desenvolvimento haviam anunciado planos de criar em seus territórios esse tipo de mecanismo de dinamização econômica. Essa tendência correspondia ao que a Unido qualificava como a "motivação dos empreendedores":

As indústrias estrangeiras ${ }^{17}$ com mercados mundiais, sendo particularmente pressionadas pelo aumento dos custos da força de trabalho, de um lado, e do aguçamento da competição nacional e internacional, de outro, estão procurando constantemente caminhos e meios de cortar ou minimizar seus custos de produção e distribuição. A racionalização da técnica de produção e dos métodos de transporte, como a "conteinerização", e a modernização da rede de vendas e distribuição são alguns exemplos desses esforços. Uma Zona Franca Industrial poderia oferecer meios adicionais de racionalização de seus custos de produção e vendas. Para que elas expandam suas bases produtivas para uma 
Zona Franca Industrial, alguns dos seguintes fatores poderiam redundar em méritos decisivos nessa direção:

a) eliminação de custos de transporte de matérias-primas;

b) eliminação de custos de transporte de bens acabados;

c) eliminação de custos de trabalho;

d) disponibilidade de abundante mão-de-obra qualificada;

e) redução do custo de investimento inicial [...] através de incentivos físicos e fiscais, da oferta de serviços e de outros tratamentos preferenciais etc. ${ }^{18}$.

De fato, essas recomendações estão, mais umas, menos outras, contempladas nas medidas de implantação da Zona Franca de Manaus. Elas encontraram, no Brasil da ditadura militar e na Amazônia economicamente estagnada, solo fértil para produzir não apenas bens para o consumo do mercado interno, mas igualmente esperanças, desconfianças e ideologias.

Admitida a hipótese de que a Zona Franca de Manaus é um momento do vasto exercício de economia política da ditadura militar no contexto da transnacionalização do capitalismo, e que a Operação Amazônia é a forma sintética da articulação entre a "ordem mundial", a "ordem nacional" e a "ordem regional", cabe pontuar, ainda que brevemente, alguns dos modos pelos quais as elites locais compreenderam esse conjunto de medidas que incluíram, também, a criação do Banco da Amazônia S.A. (Basa) ${ }^{19}$ e da Superintendência de Desenvolvimento da Amazônia (Sudam) ${ }^{20}$.

Em fotografia que retrata o lançamento da pedra fundamental do distrito industrial de Manaus, em 30 de setembro de 1968, mostra-se uma longa faixa com a seguinte inscrição: "DISTRITO INDUSTRIAL: MARCO DA REDENÇÃO DA AMAZÔNIA OCIDENTAL" ${ }^{21}$. A frase é emblemática das expectativas que as medidas adotadas pela ditadura militar na região geraram em alguns segmentos da sociedade local. Mas pode-se dizer que a possibilidade de redenção veio temperada pela de danação.

Vista como uma medida do Estado nacional brasileiro para a Amazônia, a Zona Franca de Manaus e, de modo mais amplo, a Operação Amazônia, pareciam um modo de promover o que Arthur Reis chamou de "recomposição da política federal a ser executada na Amazônia”. Em sua perspectiva, o futuro da Amazônia implicava profundas mudanças em seu comportamento, 22 daí afirmar, quando entregou o cargo de Governador do Amazonas, em 1967, que:

[...] Não poderá ela [a Amazônia], insisto sempre, comportar-se como até agora se tem comportado. É preciso dinamizar, numa mobilização homogềnea e bem coordenada dos valores espirituais e morais e das energias latentes na terra e no homem. Aquela fase predatória de sua vida, fase em que todos temos uma parcela de responsabilidade, pelo que deixamos de efetuar ou pelo que tivemos medo de efetuar, precisa ser definitivamente ultrapassada. Há que planejar, programar, promover e executar num estilo novo que nos possa permitir participar, com grandeza, do processo de desenvolvimento que dá uma feição diferente ao Brasil do Nordeste e Sul. Devemos assumir compromissos 


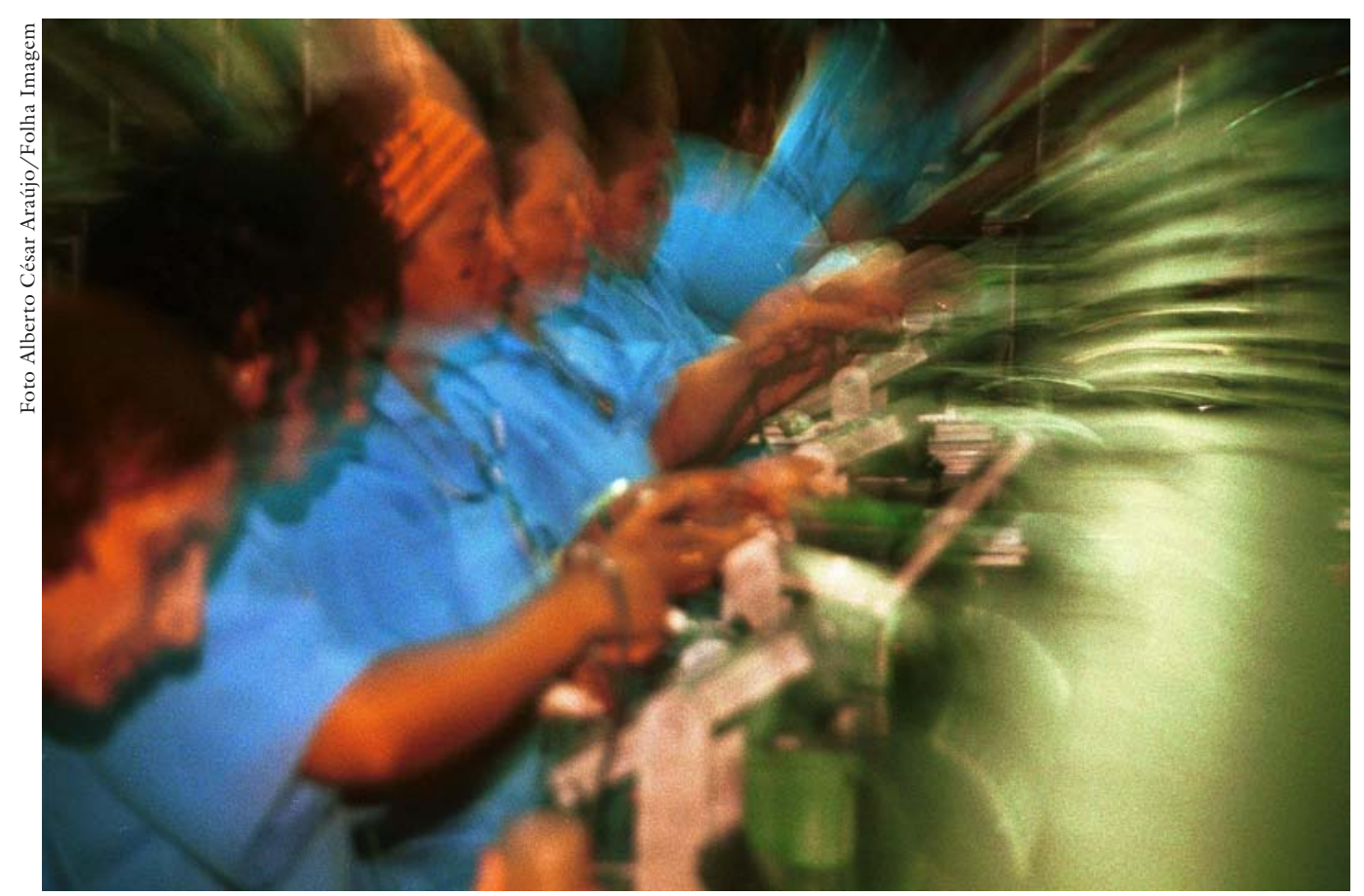

Linha de montagem de DVD da fábrica chinesa SVA, na Zona Franca de Manaus (AM).

conosco e ter decisões impetuosas, na afirmação de nossa potencialidade e de nossa capacidade para realizar. A posse da terra não pode ficar à mercê das técnicas do passado e de sistemas que não têm mais sentido algum² ${ }^{23}$.

É evidente que Arthur Reis encarna, aqui, o espírito da modernização. Olha para o "Nordeste e o Sul" e vê um outro Brasil que, progressivamente, vai se libertando das "técnicas do passado e dos sistemas que não têm mais nenhum sentido". Com efeito, Arthur Reis faz uma ampla defesa do planejamento econômico e da modernização capitalista como mudanças que devem animar, mobilizar e coordenar os "valores espirituais e morais", bem como "as energias latentes na terra e no homem". Quase diz da necessidade de converter o excedente econômico potencial representado pelas forças produtivas da região em excedente econômico efetivo através de sua apropriação e uso por meio "da iniciativa privada e da iniciativa oficial” como parte de um "esforço nacional para integrar-se, sem novos receios, no contexto brasileiro" 24 .

De modo mais sóbrio, mas não menos engajado, e preocupado especificamente com a "cultura", Leandro Tocantins também se manifesta sobre as medidas do Estado militarista para a Amazônia:

A cultura amazônica [...] sobressai na congregação dos vários Brasis com expressão singular, ecologicamente singular, que precisa ser entendida, sobretudo, pelos poderes públicos, pois à ação normativa e desenvolvimentista do Governo cabe, em primeiro plano, a responsabilidade de dinamização demográfica, social e econômica da Amazônia, desde que a Amazônia, o imenso deserto do Brasil, deve ser uma nova fronteira social e nunca individual ${ }^{25}$. 
A "fronteira social" representada pelo "imenso deserto do Brasil", a Amazônia, exigia a "ação normativa e desenvolvimentista" governamental de modo a dinamizá-la demográfica, social e economicamente e, por essa via, integrá-la, em sua singularidade, ao complexo cultural brasileiro. Quase Leandro Tocantins diz "fronteira agrícola" e fala no "vazio demográfico", noções que orientaram, de fato, a "ação normativa e desenvolvimentista" do Estado militarista para a região e que implicaram na progressiva submissão do campo à cidade, da agricultura à indústria, como parte do desenvolvimento intensivo e extensivo do capitalismo na Amazônia ${ }^{26}$.

Mas é o próprio Leandro Tocantins que, apoiado em Gilberto Freyre, adverte sobre a necessidade de se "evitar que esse prafrentismo - o termo é do próprio Tocantins - não resulte no abandono de valores tradicionais, ou no desdém pelas suas formas primitivas de manifestações" ${ }^{27}$. Diz ele:

Assim é que a integração amazônica no complexo cultural brasileiro jamais importa numa despersonalização regional, a favor de qualquer absolutismo unitário. Como disse Gilberto Freyre, nada de castelhanizar o Brasil, ou seja, o predomínio de alguma Castela - "símbolo de tendência para exagerar a unidade em detrimento da diversidade regional". Fato que o próprio sociólogo pernambucano já denunciou como "perigo da monotonia cultural ou da excessiva unificação da cultura no continente", que, segundo Gilberto Freyre, "provém do industrialismo capitalista norte-americano, largamente dominado pela idéia de que o que é bom para o norte-americano deve ser bom para os outros povos da América ${ }^{28}$.

Note-se que o “industrialismo", uma das vias da Operação Amazônia, aparece como uma ameaça à despersonalização regional decorrente da padronização da produção e do consumo que suscita. Tocantins parece chamar a atenção para os perigos representados pelo "industrialismo" como meio de converter singularidades em "massa". A questão central para ele é saber como integrar a Amazônia ao Brasil sem entregar seu "complexo cultural" ao "absolutismo unitário" do "industrialismo capitalista".

Vistas em conjunto e relevando suas diferenças, as posições de Arthur Reis e Leandro Tocantins expressam o interesse e a preocupação em compreender e propor orientações que permitam solucionar o problema da integração da região à nação, através do planejamento governamental ${ }^{29}$. Daí o apoio às medidas da Operação Amazônia: ela prometia ser uma "recomposição da política nacional para a região" ou uma alternativa de integração - e preservação - da "cultura amazônica" ao "complexo cultural brasileiro".

Com o privilégio do olhar retrospectivo, pode-se dizer que a Operação Amazônia e a Zona Franca de Manaus foram poderosos mecanismos de ajustamento das relações de produção na região às possibilidades de expansão do capitalismo monopolista no Brasil; ou, sob outro ângulo, foram formas de criar no país novas oportunidades de investimento e lucratividade para a "livre empresa", nacional e estrangeira; ou ainda, foram uma estratégia e uma tática de dinamização das 
forças produtivas regionais que consistiu - faça-se uma concessão ao neoliberalismo tupiniquim - na "redução do custo Amazônia".

É evidente que a reconstrução dessa história, ainda que em largos traços, permite pensar processos contemporâneos nos quais, novamente, o problema da formação nacional e da Amazônia se colocam. Muitos desses processos se relacionam às medidas de reforma do Estado brasileiro; e o fundamental dessa reforma é a opção das classes dominantes nacionalmente pela reiteração e aprofundamento das condições jurídico-políticas que permitem derivar o dinamismo da economia nacional da integração internacional ${ }^{30}$. $\mathrm{O}$ que levou Celso Furtado à seguinte conclusão:

Em um país ainda em formação, como é o Brasil, a predominância da lógica das empresas transnacionais na ordenação das atividades econômicas conduzirá quase necessariamente a tensões inter-regionais, à exacerbação de rivalidades corporativas e à formação de bolsões de miséria, tudo apontando para a inviabilização do país como projeto nacional ${ }^{31}$.

Com efeito, a Operação Amazônia e a Zona Franca podem ser vistas como momentos iniciais e decisivos de um processo que apontava no sentido da transição de um projeto de capitalismo nacional para outro de capitalismo associado e, no limite, de capitalismo transnacional, em que a dinâmica econômica e os centros decisórios estão fora do país. Daí que a análise de seu passado ajude a pensar muitos dos impasses e dilemas do Brasil e de suas regiões numa nova circunstância, globalizada, do desenvolvimento do capitalismo e do modo pelo qual se redefinem as relações e estruturas sociais no país. Ou, como propõe Ianni:

Esta é uma lição importante, quando se trata de entender como se realiza a transição do projeto de capitalismo nacional para o projeto de província do capitalismo global: As "elites" dominantes, compreendendo empresariais, militares, intelectuais e do alto clero revelam-se com escasso ou nulo compromisso com a nação, o povo, a sociedade. Organizam-se e movem-se como "elites" enraizadas no poder político-econômico conferido pelos monopólios, trustes, cartéis, corporações e conglomerados transnacionais; algo que vem do imperialismo e impregna amplamente o globalismo. Em sua maioria, os membros dessas "elites", isto é, classes e grupos sociais dominantes, ou blocos de poder, organizam-se ou comportam-se como conquistadores, colonizadores, desfrutadores. Estão inclinados a associar-se com os monopólios, trustes, cartéis, corporações, conglomerados; e inclinados a considerar o país, a sociedade nacional e o povo como território de negócios, pastagem de lucro, ganhos ${ }^{32}$.

É nesse quadro que se recoloca a "questão regional”, isto é, o problema de como as regiões brasileiras encontram ou vêem inviabilizadas suas possibilidades de participação - social, cultural, política e econômica - no processo de formação da nação; é nesse quadro, portanto, que cabe avaliar o passado, apontar os impasses do presente e descortinar alternativas de futuro. Trata-se, quanto a isso, de desafio semelhante ao enfrentado por Arthur Reis e Leandro Tocantins, mas que pode se beneficiar de suas experiências para evitar ilusões e ampliar os hori- 
zontes de emancipação de grupos e classes sociais historicamente excluídos dos processos decisórios e da participação na apropriação das riquezas nacionais.

\section{Notas}

1 A Zona Franca de Manaus foi criada pelo Decreto-Lei no 288 , de 28 de fevereiro

2 Celso Furtado chamou esse processo de "diáspora industrial”, cf. Celso Furtado. Brasil: a construção interrompida, $2^{a}$ ed., Rio de Janeiro, Paz e Terra, 1992.

3 BRASIL. CÂMARA DOS DEPUTADOS. Diário do Congresso Nacional (seção I), 6 ago. $1957, \mathrm{~s} / \mathrm{p}$.

4 Arthur Cezar Ferreira Reis, “A Amazônia e os problemas da projeção internacional do Brasil”, em Arthur Cezar Ferreira Reis et alli. Problemática da Amazônia, Rio de Janeiro, Livraria Editora da Casa do Estudante do Brasil, 1969, pp. 297-307, citação da p. 302.

5 Cf. Octavio Ianni, O colapso do populismo no Brasil, 5 a ed., Rio de Janeiro, Civilização Brasileira, 1994 e Francisco Oliveira, Elegia para una re(li)gión: Sudene, Nordeste. Planificación y conflictos de clases, México, D. F., Fondo de Cultura Econômica, 1982.

6 Idem, ibidem.

7 Marilene Corrêa da Silva, As metamorfoses da Amazônia, Manaus, Ed. da Ufam, 2000, p. 29.

8 Idem.

9 Cf. Ianni, op. cit., e Francisco de Oliveira, A economia da dependência imperfeita, $5^{\text {a }}$ ed., Rio de Janeiro, Graal, 1989.

10 Um dos argumentos em que se fundamenta a Exposição de Motivos n. 21/67, relativa à reestruturação da Zona Franca de Manaus, é o de que "as facilidades concedidas pelos governos estrangeiros em outras áreas limítrofes à Amazônia brasileira trouxeram um profundo surto de desenvolvimento e conseqüente êxodo de nossa população fronteiriça, para esses países”.

11 A Zona Franca de Manaus é uma zona de livre comércio e uma zona industrial. Mas existem modalidades como os portos francos, entrepostos, dentre outras. O fundamental, apesar da especificidade de cada um desses mecanismos, é que todos têm a função de oferecer condições de isenção ou redução de taxas alfandegárias, impostos e de outros custos sobre a entrada e saída de bens em dada área de um país.

12 É oportuno lembrar que o rebaixamento do custo da força de trabalho pode ser acompanhado do aumento da remuneração nominal. Isto é, do ponto de vista da empresa que investe o custo da força de trabalho se rebaixa em relação aos valores que seriam pagos para realizar o mesmo tipo de atividade nos países industrializados; do ponto de vista do trabalhador, ele pode ter sua renda aumentada em relação ao que recebia para exercer atividades outras que não aquelas desencadeadas pela zona franca. Cf. Leslie Sklair, Sociology of the Global System, Baltimore, The Johns Hopkins University Press, 1991, especialmente o terceiro capítulo, "Corporations, Classes and Consumerism", pp. 52-84. 
13 Cf. João Pinheiro Salazar, O novo proletariado industrial de Manaus e as transformações sociais possíveis (estudo de um grupo de operários). Tese de Doutorado, São Paulo, FFLCH-USP, 1992.

14 Cabe, por isso, chamar a atenção para o fato de que a estagnação econômica parece desempenhar papel central na criação e manutenção de zonas francas, isto é, ela aparece, num caso, como algo a ser superado pela implantação da zona franca e, noutro, como algo que, findos os incentivos, pode retornar; e isso inclusive em democracias representativas. Exemplo disso é notícia recentemente divulgada pela Federasul (Federação das Associações Comerciais e de Serviços do Rio Grande do Sul), dando conta da criação no país de entrepostos aduaneiros de zonas primárias: "Ficarão dentro das áreas de grandes aeroportos, poderão abrigar empresas de todos os setores e, agora vem a melhor parte, concederão isenções fiscais de até 100\%. Quando? A primeira delas começa a funcionar já em abril [de 2005], na área do aeroporto de Confins, em Belo Horizonte. As próximas serão instaladas nos aeroportos do Galeão, no Rio de Janeiro, de Petrolina, em Pernambuco, e de São José dos Campos, em São Paulo. É forte a pressão dos empresários de Campinas, a cem quilômetros da capital paulista, para a entrada do aeroporto de Viracopos no circuito das novas zonas francas".

15 A Exposição de Motivos foi elaborada por João Gonçalves de Souza (Ministro Extraordinário para a Coordenação dos Organismos Regionais), Octavio Gouveia de Bulhões (Ministro da Fazenda) e Roberto de Oliveira Campos (Ministro Extraordinário para o Planejamento e Coordenação Econômica).

16 Pode-se ter uma noção do avanço da tendência à descentralização da produção industrial e do aumento do comércio internacional proporcionado pelas zonas francas, através das estatísticas apresentadas pelo Comitê de Zonas Francas das Américas, em 2002, sobre a distribuição das zonas francas do mundo e o volume de mão-de-obra nelas ocupada:

\begin{tabular}{|lcc|}
\hline País/Região & $\begin{array}{c}\text { Número de Zonas } \\
\text { Francas }\end{array}$ & $\begin{array}{c}\text { Emprego } \\
\text { Gerado }\end{array}$ \\
\hline Estados Unidos & 713 & 315.000 \\
Ásia & 749 & 36.285 .033 \\
América Latina e Caribe & & \\
(excluindo o México) & 191 & 519.000 \\
Comunidade Econômica Européia & 55 & 43.599 \\
Economias européias em transição & 90 & 480.590 \\
Oriente Médio & 37 & 328.932 \\
Bacia do Pacífico & 14 & 13.590 \\
África & 87 & 854.975 \\
Total mundial & $\mathbf{1 . 9 3 6}$ & $\mathbf{3 8 . 8 4 0 . 7 1 9}$ \\
\hline
\end{tabular}

Fonte: Comitê de Zonas Francas das Américas (http://www.czfa.org/)

17 Foreign manufacturers, no original. Parece-nos que a referência a "indústrias estrangeiras" se justifica pelo fato de que o documento foi apresentado em seminário destinado a representantes de países que alimentavam a intenção de criar zonas francas.

18 UNIDO/ONU. SECRETARIAT OF UNIDO. Industrial Free Zones as Incentives to Promote Export-Oriented Industries. S/1: UNIDO, 28 out. 1971, mimeo, p. 9. Cf. também Renan Freiras Pinto, "Como se produzem as zonas francas", em Trabalho e produção capitalista, Belém, UFPA/ Naea, 1987, pp. 19-38 (Série Seminários e Debates, 13). 
19 Lei n⿳⺈ 5.122 , de 28 set. 1966.

20 Lei $\mathrm{n}^{\mathrm{O}} 5.173$, de 27 out. 1966.

21 Cf. Etelvina Garcia, Zona Franca de Manaus: história, conquistas e desafios, Manaus, Norma/ Suframa, 2004, p. 59.

22 É curioso notar que Arthur Reis trata a Amazônia como se falasse de uma pessoa. Na verdade, por meio desse recurso de linguagem, ele faz sua crítica às elites econômicas locais e presta apoio às mudanças que compunham a Operação Amazônia.

23 Arthur Cezar Ferreira Reis, Como governei o Amazonas, Manaus, Secretaria de Imprensa e Divulgação do Governo do Amazonas, 1967, pp. 221-222.

24 Idem, p. 303.

25 Leandro Tocantins, “A integração da Amazônia no complexo Cultural brasileiro”, em Arthur Cezar Ferreira Reis et alli, Problemática da Amazônia, Rio de Janeiro, Livraria Editora da Casa do Estudante do Brasil, 1969, pp. 149-168, citação da p. 164.

26 Cf. Octavio Ianni. Ditadura e agricultura: o desenvolvimento do capitalismo na Amazônia (1964-1978), Rio de Janeiro, Civilização Brasileira, 1979.

27 Tocantins, op. cit., p. 166.

28 Idem.

29 A propósito do problema de como o pensamento social na Amazônia compreendeu a implantação da Zona Franca de Manaus cf. Antônio Pereira de Oliveira, Zona Franca de Manaus: análise dos discursos intelectuais nas categorias Estado e desenvolvimento regional, Dissertação de Mestrado, Manaus, UFPA, 2001.

30 Diz Celso Furtado: “[... $]$ Na fase atual em que se pretende derivar o dinamismo da integração internacional, o que importa é fomentar o espírito competitivo em atividades com vocação para a exportação, o que aponta para um perfil industrial de alta capitalização e reduzido nível de emprego. Nessas circunstâncias, o que mais interessa ao empresário é obter uma elevada performance no uso dos equipamentos especializados que utiliza, e, acima de tudo, a disciplina e regularidade no trabalho, sem o que a integração transnacional se inviabiliza”. op. cit., p. 34.

31 Idem, p. 35.

32 Octavio Ianni, “O Declínio do Brasil-nação”, em Estudos Avançados 14 (40), São Paulo, 2000, pp. 51-58, citação da p. 56.

\section{Referências}

BRASIL. CÂMARA DOS DEPUTADOS. Diário do Congresso Nacional (seção I), 6/ $8 / 1957, \mathrm{~s} / \mathrm{p}$.

FREITAS PINTO, Renan. "Como se produzem as zonas francas". Em Trabalho e produção capitalista. Belém,UFPA/ Naea, 1987 (Série Seminários e Debates no 13 ), pp. 19-38.

FURTADO, Celso. Brasil: a construção interrompida. $2^{\text {a }}$ ed., Rio de Janeiro, Paz e Terra, 1992. 
GARCIA, Etelvina. Zona Franca de Manaus: história, conquistas e desafios. Manaus, Norma / Suframa, 2004.

IANNI, Octavio. “O Declínio do Brasil-nação”. Em Estudos Avançados vol. 14, no 40, São Paulo, 2000, pp. 51-58.

Ditadura e agricultura: o desenvolvimento do capitalismo na Amazônia (19641978). Rio de Janeiro, Civilização Brasileira, 1979.

ra, 1994.

. O Colapso do populismo no Brasil. 5ํㅡㄹ ed., Rio de Janeiro, Civilização Brasilei-

A Ditadura do grande capital. Rio de Janeiro, Civilização Brasileira, 1981.

MENDES, Armando (org.). A Amazônia e o seu banco. Manaus, Valer, 2002.

OLIVEIRA, Antônio Pereira de. Zona Franca de Manaus: análise dos discursos intelectuais nas categorias Estado e desenvolvimento regional. Manaus, Dissertação de mestrado apresentada ao Programa de Pós-Graduação em Sociedade e Cultura na Amazônia, da Universidade Federal do Amazonas, 2001.

OLIVEIRA, Francisco. A Economia da dependência imperfeita. $5^{\underline{a}}$ ed., Rio de Janeiro, Graal, 1989.

Elegia para uma re(li)gión: Sudene, Nordeste. Planificación y Conflictos de clases. México, D. F., Fondo de Cultura Econômica, 1982.

REIS, Arthur Cezar Ferreira et alli. Problemática da Amazônia. Rio de Janeiro. Livraria Editora da Casa do Estudante do Brasil, 1969.

REIS, Arthur Cezar Ferreira. Como governei o Amazonas. Manaus, Secretaria de Imprensa e Divulgação do Governo do Amazonas, 1967.

SALAZAR, Admilton Pinheiro. Amazônia: globalização e sustentabilidade. Manaus, Valer, 2004.

SALAZAR, João Pinheiro. O novo proletariado industrial de Manaus e as transformaçıes sociais possíveis (estudo de um grupo de operários). São Paulo, Tese de doutorado apresentada ao Programa de Pós-Graduação em Sociologia da Universidade de São Paulo, 1992.

SILVA, Marilene Corrêa. As metamorfoses da Amazônia. Manaus, Ed. da UFAM, 2000.

SKLAIR, Leslie. Sociology of the Global System. Baltimore, EUA, The Johns Hopkins University Press, 1991.

UNIDO/ONU. SECRETARIAT OF UNIDO. Industrial Free Zones as Incentives to Promote Export-Oriented Industries. S/1: UNIDO, 28 out. 1971, mimeo.

RESUMO - EXPECTATIVAS de integração à nação e ameaças de internacionalização são constantes na história da Amazônia. A Operação Amazônia e a implantação da Zona Franca de Manaus, um de seus mais emblemáticos capítulos, despertaram essas expectativas, mas também suscitaram desconfianças. Neste artigo são analisadas as condições históricas em que a Operação Amazônia e a Zona Franca de Manaus foram concebidas, além de alguns dos modos como lideranças políticas e intelectuais locais as compreenderam. Propõe-se que esses processos devam ser entendidos no quadro mais amplo de 
mudança de um modelo de capitalismo nacional para outro de capitalismo associado, o que pode ajudar na compreensão de situações contemporâneas.

Palavras-chave: Amazônia; operação Amazônia; Zona Franca de Manaus; desenvolvimento capitalista.

Abstract - THE integration to the nation and the threats of internationalization are constant issues in the history of the Amazon. The Amazon Operation and the implantation of the Manaus Free Zone, one of its most important parts, raised those expectations but also some worries. In this article the historical conditions in which the Amazon Operation as well as the Manaus Free Zone were conceived are analysed, as well as some of the ways through which local political and intellectual leaders understood them. We propose that these processes should be comprehended in reference to the change of the project of national capitalism to other of associated capitalism, what might help the understanding of contemporary situations.

Key-words: Amazon; Amazon operation. Manaus Free Zone; capitalist development.

José Seráfico é professor aposentado da Faculdade de Estudos Sociais da Universidade Federal do Amazonas e diretor executivo da Fundação Djalma Batista.

Marcelo Seráfico é doutorando em sociologia da Universidade Federal do Rio Grande do Sul. @ - serafico@uol.com.br

Texto recebido em 30/4/2005 e aceito em 30/5/2005. 